${ }^{1}$ P M Morfeld, ${ }^{1}$ Noll, ${ }^{2}$ Koch, ${ }^{2}$ Erren. ${ }^{1}$ Evonik Industries AG, Essen, Germany; ${ }^{2}$ University of Cologne, Cologne, Germany

\subsection{6/oemed-2013-101717.58}

Objectives To determine the relationship between exposure to hard-metal dusts and lung cancer mortality. This international cohort study is coordinated by the Universityof Pittsburghand funded by the International Tungsten Industry Association (Marsh et al 2013, EPICOH abstract). The German component comprises three Kennametal manufacturing sites in North RhineWestphalia and Bavaria.

Methods We enrolled all current and former workers at two Bavarian sites (start of production 1960 and 1971 respectively). At the largest plant in North Rhine-Westphalia (start of production 1926) we will enrol all blue-collar workers who were employed for at least 6 months. We will collect and analyse measurement data, work history, and medical information like smoking and urine data. We will apply an electronic data collection system to protect personal data. To investigate total and cause-specific mortality for the period 1980-2011, we aim to determine each subject's vital status and, if applicable, cause of death. External comparisons (SMRs) to the German population and state populations will be performed. Cox models will be used for internal analyses.

Results Our preliminary estimates of the numbers of participants at the two Bavarian plants are 2,711 and 1,577. At the North Rhine-Westphalian plant we have enrolled 3,700 workers (less than half of the overall workforce). Some current workers refused to be enrolled in the study. 3.7\% of 676 and $0.2 \%$ of 417 at Bavarian plants and $0.9 \%$ of 637 at North Rhine-Westphalian plant. Basic data of these workers will be documented. Conclusions The data collection process in North Rhine-Westphalia was restricted due to the large number of paper files. Otherwise it would not be feasible to meet the budget and time schedule of the international pooling project. Vital status and cause of death tracing are challenging in Germany. We will try to optimise procedures in cooperation with the responsible institutions.

\section{AN INTERNATIONAL HISTORICAL COHORT STUDY OF WORKERS IN THE HARD-METAL INDUSTRY - AUSTRIAN COMPONENT}

${ }^{1} \mathrm{H}$ M Moshammer, ${ }^{2}$ Buchanich, ${ }^{3}$ Kennedy, ${ }^{3}$ Esmen, ${ }^{2}$ Marsh. ${ }^{1}$ Med Univ Vienna, Vienna, Austria; ${ }^{2}$ Univ Pittsburgh, Pittsburgh, United States of America; ${ }^{3}$ University of Illinois, Chicago, United States of America

\subsection{6/oemed-2013-101717.59}

Objectives Researchers at the University of Pittsburgh and the University of Illinois at Chicago are coordinating an international historical cohort study of workers in the hard-metal industry. Funding is provided in part by the International Tungsten Industry Association. From Austria they approached a large industrial plant in Reutte, Tyrol, and the Institute of Environmental Health at the Medical University of Vienna to coordinate the Austrian part of the study that is financially supported by the national workers insurance company.

Methods As a first result of the cooperation between Reutte and Vienna a cross-sectional study was designed based on a questionnaire directed to all present workers and to past workers with still valid addresses. This questionnaire served two purposes: (1) to announce the aim of the cohort study and (2) to obtain more detailed data on smoking history and general health history than is available in the company records.

Results In spite of repeated advertising of the questionnaire by the Reutte management only approximately $10 \%$ of all addressees (233 persons in total) responded. Active workers were overrepresented while only 78 (mostly only recently) retired workers completed the questionnaire. Also, current white collar (office) workers were overrepresented (58 persons).

Conclusions Although a respiratory disease or hypertension were each reported by about $10 \%$ of respondents the subjective health status was generally good. Better health was reported by office workers while working in departments with the highest dust exposure was not associated with poorer health. Increasing age did not consistently lead to higher symptom rates while smokers reported poorer health not only for respiratory but also for rheumatic and psychiatric symptoms.

We will also report on the progress of our ongoing work on the international epidemiology study.

\section{CANCER MORBIDITY OF LEAD EXPOSED WORKERS IN KOREA}

${ }^{1} Y$ S Ahn, ${ }^{2}$ Kim. 'Dongguk University Ilsan Hospital, Goyang, South Korea; ${ }^{2}$ Dongguk University Gyeongju Hospital, Gyeongju, South Korea

\subsection{6/oemed-2013-101717.60}

Objectives To compare cancer patterns in lead exposed workers with the Korean general population, and to explore the relationship between cancer and lead exposure in an occupational setting.

Methods Using from the Korean annual medical surveillance for exposure to lead, a cohort comprising 75,184 lead exposed workers working between January $1^{\text {st }}, 2000$ and December $31^{\text {st }}$, 2004 was compiled. This cohort was merged with the Korea National Central Cancer Registry (KNCCR) in order to evaluate the cancer morbidity for these workers between 2000 and 2008. Results Therewere 793 cases cancer and, the incidence of stomach cancer (SIR 1.17, 95\% CI $=1.01-1.36$ ) was found to be elevated in lead chromate workers. Excesses were observed for kidney (2.15.1.19-3.88) and bladder cancers (2.29.1.149-4.58) in lead exposed workers $\geq 20$ years of job duration, kidney cancer (2.25.1.21-4.18)in workers with $\geq 10 \mathrm{ug} / \mathrm{dl}$ of blood lead level and lung cancer in female workers with $\geq 10 \mathrm{ug} / \mathrm{dl}$ blood lead level.

Conclusions Our study showed excess of lung cancer in female workers, stomach cancer in lead chromate exposed workers and a possible dose-response relationship between d kidney cancers and lead exposure.

\section{AN INTERNATIONAL HISTORICAL COHORT STUDY OF SWEDISH WORKERS IN THE HARD-METAL INDUSTRY}

${ }^{1}$ B T Westberg, ${ }^{2}$ Svartengren, ${ }^{3}$ Marsh, ${ }^{3}$ Buchanich, ${ }^{4}$ Kennedy, ${ }^{4}$ Esmen. ${ }^{1}$ Örebro, Sweden; ${ }^{2}$ Karolinska Institute, Stockholm, Sweden; ${ }^{3}$ University of Pittsburgh, Pittsburgh, United States of America; ${ }^{4}$ University of Chicago, Chicago, United States of America

\subsection{6/oemed-2013-101717.61}

In 2006, IARC found limited evidence in humans and sufficient evidence in animals that tungsten carbide (WC) with cobalt binder (WCCo) acted as a lung carcinogen (Group 2A). A Swedish historical cohort study was established as part of the international cohort. Three Swedish sites are included, 